\title{
1 Hydrologic response to stormwater control measures in urban watersheds
}

\section{Colin D. Bell ${ }^{1}$, Sara K. McMillan ${ }^{1}$, Sandra M. Clinton ${ }^{2}$ and Anne J. Jefferson ${ }^{3}$}

1. Department of Agricultural and Biological Engineering, Purdue University, 225 S. University Street, West Lafayette, IN 47907, USA

2. Department of Geography and Earth Sciences, University of North Carolina at Charlotte, 9201 University City Boulevard, Charlotte, NC 28223, USA

3. Department of Geology, Kent State University, 221 McGilvrey Hall, Kent, OH 44242, USA

Keywords: stormwater management; urban hydrology; impervious surfaces; runoff mitigation; best management practices

\section{Abstract}

Stormwater control measures (SCMs) are designed to mitigate deleterious effects of urbanization on river networks, but our ability to predict the cumulative effect of multiple SCMs at watershed scales is limited. The most widely used metric to quantify impacts of urban development, total imperviousness (TI), does not contain information about the extent of stormwater control. We analyzed the discharge records of 16 urban watersheds in Charlotte, NC spanning a range of TI (4.1 to $54 \%)$ and area mitigated with SCMs (1.3 to $89 \%)$. We then tested multiple watershed metrics that quantify the degree of urban impact and SCM mitigation to determine which best predicted hydrologic response across sites. At the event time scale, linear models showed TI to be the best predictor of both peak unit discharge and rainfall-runoff ratios across a range of storm sizes. TI was also a strong driver of both a watershed's capacity to buffer small (e.g., 1-10 mm) rain events, and the relationship between peak discharge and precipitation once that buffering 
23 capacity is exceeded. Metrics containing information about SCMs did not appear as primary

24 predictors of event hydrologic response, suggesting that the level of SCM mitigation in many

25 urban watersheds is insufficient to influence hydrologic response. Over annual timescales,

26 impervious surfaces unmitigated by SCMs and tree coverage were best correlated with

27 streamflow flashiness and water yield, respectively. The shift in controls from the event scale to

28 the annual scale has important implications for water resource management, suggesting that

29 overall limitation of watershed imperviousness rather than partial mitigation by SCMs may be

30 necessary to alleviate the hydrologic impacts of urbanization.

\section{$31 \quad 1 \quad$ Introduction}

32 Urbanization alters the response of river networks to hydrometeorological drivers, causing more

33 frequent and intense floods (Leopold, 1968). This new flood regime causes more stream bank

34 erosion, destroys habitat, and subsequently degrades stream ecosystem health (Paul and Meyer,

35 2001). Runoff generated during storm events is quickly concentrated in pipes and stream

36 networks by stormwater drainage systems, which produce elevated peak flows and cause

37 flooding and infrastructure damage. Additionally, urbanization can lead to rising or falling

38 baseflow, which affects stream ecosystems by changing temperatures and nutrient cycling

39 (Bhaskar et al., 2016). Stormwater control measures (SCMs) mitigate the impacts of urbanization

40 by attenuating storm volumes, reducing peak discharges, accelerating groundwater recharge, and

41 promoting evaporation (Roesner et al., 2001; Hamel et al., 2015). However, the capacity for

42 SCMs to restore natural hydrologic regimes and stream ecosystem functions depends on both the

43 extent of implementation within the watershed and the degree of impact from urbanization

44 (Roesner et al., 2001; Hur et al., 2008; NRC, 2008; Roy et al., 2008; Burns et al., 2012). 
45 Total imperviousness (TI), which is the fraction of the watershed area covered by an impervious

46 surface, has often been used as a way to quantify the degree of urbanization. It is both integrative

47 and easily measurable (Arnold and Gibbons, 1996). While the form of the relationship between

48 stream degradation and TI is uncertain (e.g., linear or having a threshold after which degradation

49 begins), it is well established that stream degradation does increase with TI (Schueler, 1995; May

50 et al., 1997; Booth et al., 2002). As reviewed by Paul and Meyer (2001), TI increases runoff

51 magnitude manifested as peak discharge, bankfull discharge, and runoff ratio at both event and

52 annual time scales. The lag time between rainfall and runoff generation has also been shown to

53 shorten with increasing TI (Espey et al., 1966; Leopold, 1968). In a review of urban streams in

54 the U.S. Southeast, O’Driscoll et al. (2010) demonstrated that these hydrologic changes have

55 cascading effects on stream ecosystems by altering channel geomorphology, reducing the ability

56 of streams to retain and remove nutrients, and decreasing the abundance of intolerant

57 macroinvertebrate taxa.

58 One criticism of TI as a metric for predicting stream response is that not all impervious surfaces

59 are directly connected to drainage networks through surface conveyance channels or pipes. An

60 example of a disconnected impervious surface is the rooftop of a building that is surrounded by

61 vegetation on all sides. Effective imperviousness (EI) accounts for this important nuance in

62 impervious surface connectivity and is defined as the portion of the watershed covered by

63 impervious surfaces directly connected to the drainage network (Alley et al., 1980; Alley and

64 Veenhuis, 1983; Shuster et al., 2005; Walsh et al., 2005). As with TI, EI is an integrative

65 measure characterizing urbanization, however it is not as easily quantified because it requires

66 information on the connectivity of impervious surfaces. 
67 SCMs are designed to produce hydrographs that mimic pre-development conditions, therefore

68 impervious surfaces mitigated by SCMs are assumed to be disconnected from the streams when

69 computing EI (Walsh et al., 2005). SCMs take many forms (e.g. wet ponds, dry ponds,

70 bioretention areas), but are generally hydrologically connected elements within the landscape

71 that temporarily store and release water to the drainage network at a slower rate determined by

72 the size and design of the SCM and its outlet structure. This process of water attenuation reduces

73 peak flows, and increases lag times between precipitation and stormflow volumes (Horner et al.,

74 2001; Villarreal et al., 2004; Hood et al., 2007; Jarden et al., 2015). However, the water balance

75 of urban watersheds is often still perturbed, because of the leakage of imported drinking water

76 through distribution pipes and decreased evapotranspiration, unless the SCMs include a

77 significant water harvest or reuse component (Askarizadeh et al., 2015).

78 Accurately quantifying EI for large areas is time consuming and requires knowledge of roof

79 downspout connections and pipe networks (Lee and Heaney, 2003). Therefore, simply

80 distinguishing unmitigated impervious areas from mitigated ones may be a simple way to derive

81 a watershed metric similar to EI. Here were propose an additional metric: unmitigated

82 imperviousness (UI), which is the fraction of total watershed area occupied by impervious

83 surfaces that are not mitigated by SCMs. The ratio of UI/TI, then, is the fraction of impervious

84 area that is unmitigated by SCMs. This ratio is analogous to the directly connected impervious

85 areas fraction (often abbreviated DC, DCI or DCIA) used in other studies (Lee and Heaney,

86 2003; Walsh et al., 2005; Walsh and Kunapo, 2009; Shields and Tague, 2014).

87 Because UI and EI contain additional information about connectivity and the role of SCMs, they

88 may explain the difference in hydrologic response to rainfall between sites better than TI.

89 However, neither contains information about treated pervious areas. Inclusion of the treated 
90 pervious areas is important, particularly in residential urban and suburban environments, where

91 lawns occupy on average $23 \%$ of the area (Robbins and Birkenholtz, 2003). During

92 construction, lawns are compacted which reduces infiltration and contributes to excess runoff

93 (Pitt et al., 2008). Hence, treating surface runoff from these pervious, but potentially runoff-

94 yielding areas may mitigate peak flows. Therefore, quantifying the mitigated area (MA) of the

95 watershed may prove to be useful for characterizing the benefits of treated pervious and

96 impervious areas.

97 We hypothesized that if stormwater management is affecting urban hydrology, then metrics that

98 include both urbanization and SCM mitigation will explain variation in hydrologic response

99 variables across sites better than those that quantify either urbanization or SCM mitigation alone.

100 Specifically, we predicted that MA, which accounts for potential storage of runoff from pervious

101 and impervious surfaces in SCMs, would be most closely correlated with runoff volume. Also,

102 we predicted that UI would best explain variation in peak discharge and record flashiness

103 because it enumerates the potential for impervious surface runoff to bypass SCMs and flow

104 efficiently to the stream. In addition, water resource managers seeking to limit the impacts of

105 urbanization can use the metrics that best explain hydrologic response to SCM mitigation in a

106 planning and policy development.

\section{Site Descriptions}

108 We examined 16 watersheds with SCMs in the Charlotte, North Carolina (35 $13^{\prime} 36.9^{\prime \prime} \mathrm{N}, 80^{\circ}$

$109 \quad 50$ ' 35.9" W) metropolitan region in the Piedmont physiographic province (Figure 1). Between

1101971 and 2000, Charlotte's mean annual precipitation was $1105 \mathrm{~mm}$ and was distributed evenly

111 across months. Over the same time period, the average daily temperature was $16.4^{\circ} \mathrm{C}$ annually, 
112 and $5.4^{\circ} \mathrm{C}$ and $26.8^{\circ} \mathrm{C}$ for the months of January and July respectively (State Climate Office of

113 North Carolina, 2013).

114 Of the 16 sites selected for hydrological analysis, streamflow was recorded at 12 of them by the

115 United States Geologic Survey (USGS) (Table 1). These twelve sites had drainage areas ranging

116 from $2.5 \mathrm{~km}^{2}$ to $32.9 \mathrm{~km}^{2}$ and were selected to span a range of urban development and SCM

117 density. Little Sugar Creek drains Charlotte's city center and serves as an upper bound on urban

118 development intensity in the city. Only $14 \%$ of the Reedy Creek watershed is developed (Table

119 1), and it was included as a control against any effects that watershed size may have on the

120 results at Little Sugar Creek.

121 In addition to the 12 USGS sites, we included 4 smaller streams that were gaged as part of a

122 larger study of the impacts of SCMs on multiple ecosystem services. Two of these four

123 watersheds, UP1 $\left(1.4 \mathrm{~km}^{2}\right)$ and UL1 $\left(1.5 \mathrm{~km}^{2}\right)$, were adjacent to one another and are

124 subwatersheds of Edward's Branch and Campbell Creek, respectively. The other two, SP1 (1.0

$\left.125 \mathrm{~km}^{2}\right)$ and SL1 $\left(0.15 \mathrm{~km}^{2}\right)$, were drained by a tributary to Beaverdam Creek (BD4), which flowed

126 into Beaverdam Creek downstream of a USGS gage used in this study. Changes to the

127 hydrology and water quality during urbanization and contributions of SCM water to streamflow

128 during storm events have been the topics of past studies at BD4 (Allan et al., 2013; Gagrani et

129 al., 2014; Jefferson et al., 2015). We included these highly treated sites because they are smaller

130 than watersheds typically gaged by the USGS. Also, EI can be estimated at this scale with a few

131 simplifying assumptions, but is not practical for larger watersheds with complex engineered

132 drainage networks. This allows us to use these sites to test the ability of other metrics to serve as 133 a proxy for EI. 
134 Drainage areas were calculated using the Hydrology Toolbox in ArcGIS (ESRI, Redlands, CA,

135 USA) with a $6.1 \mathrm{~m}(20 \mathrm{ft})$ digital elevation model (DEM). For the all sites, spatial data from the

136 City of Charlotte identifying the location of underground pipe networks was burned into the

137 DEM prior to automatic delineation. For the highly treated sites, we manually adjusted

138 watershed boundaries to incorporate additional knowledge of the underground storm sewer

139 networks from field visits, aerial imagery and stormwater pipe network data. These manual

140 adjustments were made at the small, highly treated sites because misidentification of watershed

141 area there could produce large relative errors when calculating metrics such as TI, EI, UI and

142 MA.

143 TI was determined from two spatial datasets: the first is a remote sensing land cover map

144 developed for the year 2012 by Mecklenburg County, and the second is a vector shapefile of

145 impervious surfaces used for stormwater taxation developed by the City of Charlotte. Tree

146 coverage was also derived from the Mecklenburg County land coverage map.

147 The location and extent of SCMs and corresponding drainage areas were taken from a database

148 compiled by the City of Charlotte Division of Storm Water Services, accessed upon its first

149 release in July 2015. This dataset was created from records kept by the City of Charlotte's

150 Division of Land Management in compliance with the city's post-construction stormwater

151 ordinances. The dataset is also linked to spatial data outlining the drainage area that each SCM

152 mitigates, which was determined using a combination of high-resolution topographic data and

153 site designs provided by developers in accordance with the post-construction ordinance. In

154 addition to the City's database, we used aerial photos available via Google Earth (Google Inc.,

155 2015) dating from 1993 to 2012 to identify any SCMs in the watersheds missing from the 
156 database. We manually delineated drainage basins and calculated drainage area for these

157 additional SCMs using pipe network data, aerial photos, and elevation data.

158 Only SCMs designed to add storage were included when determining SCM mitigated area, while 159 conveyance SCMs (e.g. swales) were left out. A number of in-line ponds existed in Charlotte,

160 but were not considered SCMs unless they were included in the City's pond rehabilitation

161 program, which retrofits ponds with either an outlet weir, littoral zone vegetation, or both to

162 provide water quantity and quality benefits. We used the spatial datasets of SCM mitigated area

163 and TI to compute UI and UI/TI at all 16 sites.

164 We estimated EI at the highly treated sites only using the following simplifying assumptions: (1)

165 all impervious surfaces within an SCM drainage area were considered to be not effective; (2) all

166 hydrologically remote, disconnected impervious surfaces were considered to be not effective; (3)

$167100 \%$ of roads and parallel sidewalks drained by pipe networks leading directly to a stream were

168 considered effective; (4) single-family residential rooftops with driveways tangent to an

169 unmitigated road were assumed to be $50 \%$ connected on lots $\leq 1 / 4$ acre and $33 \%$ connected on lots

$170>1 / 4$ acre, but the driveways were assumed $100 \%$ effective at both parcel classifications; and (5)

171 other larger, multi-family residential and commercial buildings and associated parking lots were

172 considered $80 \%$ connected. These assumptions were based on field observations and aerial

173 photographs, and applying these assumptions produced land use specific EI estimates

174 comparable to those of Alley and Veenhuis (1983) for 19 urban watersheds in Denver, CO, USA.

\section{Data and Analysis}




\subsection{Data Sources}

177 At the highly treated sites, a period of approximately one year (2011-2012) was used for

178 hydrologic analysis. The period was slightly different for each site, running from 6/21/11 to

$1795 / 1 / 12$ at UP1, $6 / 20 / 11$ to $6 / 20 / 12$ at UL1, $9 / 27 / 11$ to $9 / 27 / 12$ at SP1 and 8/18/11 to 8/18/12 at

180 SL1. These time periods were chosen to include dates of stormwater quality sampling done as

181 part of a companion study. At the USGS sites, the 2012 water year was selected for analysis, as

182 it is the water year that corresponds best with the records selected at the highly treated sites.

183 Data from Charlotte Douglas Airport (station ID: KCLT, downloaded from

184 http://www.ncdc.noaa.gov/cdo-web/) indicated that the $960 \mathrm{~mm}$ of water fell during the 2012

185 water year, which was the $25^{\text {th }}$ percentile of total annual precipitation on the station's 72 -year

186 record.

187 For the USGS sites, approved instantaneous discharge data, measured at 15-minute intervals,

188 were downloaded from the USGS National Water Information System

189 (http://nc.water.usgs.gov/char/streamflow.html). At the highly treated sites, we recorded stream

190 stage at 10-minute intervals using a 730 Bubbler Module Sensor attached to an ISCO

191 autosampler (Teledyne Technologies Inc., Thousand Oaks, CA, USA). We developed stage-

192 discharge relationships for each site using a HEC-RAS (US Army Corps of Engineers) hydraulic

193 model built from cross sectional geometry data collected at approximately $1.5 \mathrm{~m}$ longitudinal

194 intervals. The modeled Manning's roughness coefficient for the channel banks was calibrated to

195 match four to five high storm flow observations collected using velocity-area and dilution gaging

196 methods (USGS, 1982). For calibrating Manning's roughness in the channel at low flows, the

197 total unit stormflow volume contributed from flows less than the $90^{\text {th }}$ percentile discharge value

198 was calibrated to be within $\pm 10 \%$ of the observed annual unit discharge from nearby gages over 
199 the same period. The USGS gage at Edward's Branch was used for calibration of low flows at

200 UL1 and UP1, since the watersheds are adjacent and have similar land use and stormwater

201 infrastructure. The USGS Edward's Branch gage was located $0.4 \mathrm{~km}$ downstream from UL1. For

202 the two suburban sites, the record for low-flow calibration was compiled from a capacitance

203 water level record combined with a stage-discharge rating curve by Gagrani et al. (2014) for the

204 BD4 watershed.

205 We used 5-minute precipitation data from 31 rain gages in the USGS National Water

206 Information System (NWIS) (http://nc.water.usgs.gov/char/raingage.html) to construct

207 composite precipitation records for each watershed using the Thiessen method (Thiessen, 1911)

208 (Figure 1). The number of gages used to create the area-weighted composite record at a given

209 site ranged from 1 to 8.

\section{$210 \quad 3.2$ Hydrologic Variables Considered}

211 To characterize the hydrologic response, we first developed a procedure to identify individual

212 storm events. We modified the constant line separation method developed by Hewlett and

213 Hibbert (1967) to separate stormflow from baseflow and to define the end of a hydrologic event

214 (Figure 2). This method was originally applied in forested watersheds to separate stormflow from

215 baseflow, but because response times are considerably faster in urban streams, we decreased the

216 slope of the separation line to $3.3 \times 10^{-5} \mathrm{~m}^{3} \mathrm{~s}^{-1} \mathrm{~km}^{-2} \mathrm{hr}^{-1}$ based on observations of a subset of

217 individual events at each site. We defined the initiation of an event as the time of the first

218 positive hydrograph slope during a 60-minute period that exceeded the slope of the hydrograph

219 separation line. We determined the end of the event as the time when the separation line

220 intersected the hydrograph. Of all hydrologic events identified, we retained only events in which

221 total precipitation $\left(\mathrm{PPT}_{\mathrm{E}}\right)$ exceeded $2.54 \mathrm{~mm}(0.1 \mathrm{in})$ for analysis. While other hydrograph 
222 separation methods using digital filters exist (Lyne and Hollick, 1979; Eckhardt, 2005), these

223 methods are not designed to determine the start and end of individual storm events at a sub-daily

224 time step.

225 Using the discharge and precipitation data, we derived several metrics of event-scale hydrologic 226 response. First we calculated the rainfall-runoff ratio as shown in Eq. 2:

$227 \quad$ Runoff Ratio $=\frac{V / A}{P P T_{E}}$

228 where $\mathrm{V}$ is the total stormflow volume $\left[\mathrm{L}^{3}\right]$ above the separation line (Figure 2 ), $\mathrm{A}$ is the

229 watershed area $\left[\mathrm{L}^{2}\right]$, and $\mathrm{PPT}_{\mathrm{E}}$ is the total event precipitation $[\mathrm{L}] . \mathrm{PPT}_{\mathrm{E}}$ was the sum of all rain

230 falling during the defined hydrologic event and any rain that had fallen $1.5 \mathrm{~h}$ prior to the event.

231 Using this $1.5 \mathrm{~h}$ time window, pre-event precipitation accounted for $<10 \%$ of total event rainfall

232 for $75 \%$ of events analyzed.

233 We defined peak discharge as the largest instantaneous discharge value during the hydrologic

234 event and normalized it to watershed area to allow for comparisons across sites. We calculated a

235 "response rate" using the slope of a log-transformed linear model of peak discharge vs.

236 maximum 60-minute precipitation intensity $\left(\mathrm{I}_{60}\right)$. This precipitation metric was chosen over

$237 \mathrm{PPT}_{\mathrm{E}}$ and the maximum 15-minute precipitation intensity as it produced the highest $\mathrm{R}^{2}$ values at

2389 of the 16 sites. We also estimated the amount of storage within the watershed as the threshold

239 of precipitation above which streamflow responds more rapidly to rainfall (Loperfido et al.,

240 2014). We calculated this as the breakpoint in slope of piecewise linear models between peak

241 discharge and total precipitation using the "segmented" package in R (R Core Team, 2013). For 
242 computation of these breakpoints only, precipitation events with $\mathrm{PPT}_{\mathrm{E}}$ less than $2.54 \mathrm{~mm}$ were

243 also included.

244 In addition to these event-specific metrics, we computed two metrics to describe hydrologic

245 behavior over longer timescales. We computed the annual water yield ratio as the slope of the

246 regression line fit between cumulative daily flow depth and cumulative daily precipitation.

247 Additionally, we calculated the percent of time the instantaneous discharge was above the mean

248 value to characterize flashiness, a metric that can be used to describe the regime of hydrologic

249 disturbances to stream ecosystems and is also tied to ecosystem biological integrity (Booth et al.,

250 2004; Cassin et al., 2005; Burns et al., 2015).

\section{$251 \quad 3.3$ Statistical Analysis}

252 We used the software R (R Core Team, 2013) to perform all statistical analyses and all results

253 reported as significant are within $95 \%$ confidence unless otherwise indicated. To determine

254 trends across sites, we fit both linear and log-transformed linear models through the hydrologic

255 response variables using the eight watershed metrics (Table 2). The watershed metric producing

256 a univariate model with the highest performance determined by $\mathrm{R}^{2}$ was deemed the primary

257 control on hydrologic behavior across sites. Only univariate models were tested because the site

258 factors were highly correlated (Table 3) and using two or more of these variables would

259 introduce multicollinearity. Instead, we performed a correlation analysis between the residuals of

260 the linear models and the each of the remaining watershed metrics to identify secondary controls.

261 All correlations were quantified using the Pearson product-moment correlation coefficient (R).

262 We computed 6 percentiles $\left(10^{\text {th }}, 30^{\text {th }}, 50^{\text {th }}, 70^{\text {th }}, 90^{\text {th }}\right.$ and $\left.99^{\text {th }}\right)$ for peak discharge and runoff

263 ratio at all 16 sites. We then performed the linear modeling procedure outlined above on all 
264 these percentile values ( 6 models per variable, each with $n=16$ ) to characterize the primary and

265 secondary control across the entire range of event scale observations, rather than just

266 characterizing the mean or median. Performing this analysis across the distribution of hydrologic

267 variables allowed us to identify which watershed factors controlled hydrologic response under

268 varying antecedent moisture, temperature, and precipitation characteristics, which contribute to

269 the variability within each site.

2704 Results

\section{$271 \quad 4.1$ Watershed metrics}

272 All of the watersheds metrics considered characterized either the intensity of urbanization, SCM

273 mitigation or both (Table 1), and several of them correlated with each other (Table 3). The level

274 of urbanization, quantified by TI, spanned from $4 \%$ to 51\%. Mitigated Area (MA) ranged from

2751.3 to $89 \%$, but only three sites (all from the highly treated sites group) had MA values $>20 \%$.

276 EI, computed at only the 4 highly treated sites, ranged from $0.2 \%$ at SL1 to $41 \%$ at UL1. UI

277 ranged from $0.48 \%$ to $52 \%$. UI was very strongly correlated with EI (Table 3), which indicates

278 that it can serve as a suitable replacement for EI if SCMs are assumed to convert effective

279 impervious areas into non-effective ones. UI and TI were also strongly correlated, and UI

280 averaged $77 \%$ of TI. TI and tree coverage were moderately negatively correlated.

\section{$281 \quad 4.2$ Runoff Ratios}

282 For the analysis period, across 16 sites, we identified a total of 737 hydrologic events with

283 precipitation $\geq 2.54 \mathrm{~mm}$. Of the eight watershed metrics, TI was the best predictor of the $10-90^{\text {th }}$

284 percentile runoff ratios, and runoff ratios increased with increasing TI (Figure 3a, Table 4). No

285 significant relationship was produced for $99^{\text {th }}$ percentile storms, which were highly variable. 
Additionally, the coefficient of variation of runoff ratios decreased with increasing $T I\left(\mathrm{R}^{2}=0.57\right.$,

$287 \mathrm{p}<0.001)$. Significant linear models were also identified for the $30^{\text {th }}-90^{\text {th }}$ percentile runoff ratios

288 using UI as the independent variable, and for the $10^{\text {th }}-90^{\text {th }}$ percentiles using tree coverage

289 fraction. Runoff ratios increased with increasing UI and decreased with increasing tree cover.

290 These models had lower explanatory power $\left(\mathrm{R}^{2}\right)$ than the TI models. No significant relationships

291 were identified for any runoff ratio percentile versus MA, SCM density or UI/TI.

292 To identify secondary controls on the $10-90^{\text {th }}$ percentile runoff ratios, we correlated the residuals

293 of the runoff ratio-TI models with the remaining site metrics. Residuals were most strongly

294 correlated with the ratio of UI/TI (i.e., the percentage of impervious area that was unmitigated by

295 SCMs). All correlations were negative $(-0.46 \leq \mathrm{R} \leq-0.63)$, which indicated that sites with a higher

296 ratio of unmitigated imperviousness to total imperviousness had higher runoff ratios (Figure 3b).

\section{$297 \quad 4.3$ Peak Discharge}

298 Across all events and watersheds, simple linear regression models show peak discharge to be 299 most strongly predicted by TI at all percentiles (Figure 4a, Table 4). In addition, significant 300 models with lower explanatory power $\left(\mathrm{R}^{2}\right)$ were identified for UI $\left(10^{\text {th }}-70^{\text {th }}\right.$ percentiles $)$ and 301 tree coverage $\left(10^{\text {th }}-90^{\text {th }}\right.$ percentiles $)$.

302 Correlation with the residuals of the peak discharge-TI models identified multiple secondary 303 controls, changing with event size. Watershed area was identified as the strongest secondary 304 control for smaller peak flows $\left(10^{\text {th }}-50^{\text {th }}\right.$ percentiles, $R<-0.53$, shown in Figure $\left.4 b\right)$. Larger peak 305 flows $\left(70^{\text {th }}\right.$ and $90^{\text {th }}$ percentiles) were inversely correlated to SCM density $(\mathrm{R}=-0.414$ and -0.594 , 306 respectively, Figure 4c), and the $99^{\text {th }}$ percentile was best correlated to the tree coverage 
307 ( $R=0.556$, Figure $4 d)$. However, the correlations for the $70^{\text {th }}-90^{\text {th }}$ percentiles were strongly

308 leveraged by one point.

309 Despite the shifting secondary control, when plotted against watershed area, the peak flow-TI

310 residuals for all percentiles generally declined as area increased (Figure $4 \mathrm{~b}$ ). This indicated that

311 as watershed size shifted from small to large, the TI model shifted from under-predicting to over-

312 predicting peak discharge. However, below $2 \mathrm{~km}^{2}$, the trend was reversed, potentially due to the

313 high level of SCM mitigation at the small, highly treated sites.

\section{4.4 Peak Discharge Response to Precipitation Across Sites}

315 Two record-long metrics were used to characterize the form of the relationship between peak

316 discharge and precipitation characteristics. First, we defined the discharge response rate as the

317 slope of the linear model of peak discharge (log-transformed) and $\mathrm{I}_{60}$. This site-specific variable

318 ranged from 0.59 at Gar Creek to 1.65 at Briar Creek Trib. As with the event scale metrics, the

319 primary site factor that best predicted this variable across sites was TI $\left(\mathrm{R}^{2}=0.54, \mathrm{p}=0.001\right.$, Figure

320 5). Significant, but weaker linear models were also observed between the response rate and UI.

321 The second metric describing the relationship between rainfall and peak discharge was the

322 breakpoint in the slope of a linear model of peak unit discharge and $\mathrm{PPT}_{\mathrm{E}}$. Examples of this

323 break in slope are shown for sites at the opposite ends of the urbanization spectrum. Figure 6a

324 shows that Gar Creek, with $4 \%$ TI, had a flatter slope between 0 and $12 \mathrm{~mm}$ of rain, above which

325 the stream responded at a higher rate. Little Sugar Creek, with 54\% TI, shifted at precipitation

326 levels as low as $1 \mathrm{~mm}$ (Figure 6b). Our data showed that with increasing TI, runoff generation

327 and streamflow response occurred during smaller rain events (Figure 6c). There was a

328 downward trend in the breakpoint as TI increased. Determining the primary site metric 
329 controlling the breakpoints across site was difficult, as a number of sites did not exhibit a

330 significant breakpoint (Figure 6c). Using subsets of the data based on breakpoint significance,

331 TI consistently showed the strongest correlation with the breakpoint.

\section{$332 \quad 4.5$ Annual Metrics}

333 Two annual hydrologic metrics (water yield and time above mean) were also computed. Of all

334 eight site metrics tested, water yield was most strongly correlated with tree coverage $\left(R^{2}=0.53\right.$,

$335 \mathrm{p}=0.002$ ) (Figure 7a). TI and UI also produced significant linear models, but with poorer

336 performance.

337 The second annual metric considered was the fraction of time the hydrologic record spent above

338 the mean discharge. This metric is an indication of flashiness with low values representing rapid

339 watershed response (e.g., higher peaks and shorter duration). The time above mean ranged from

$3407.1 \%$ at Edwards Branch to $31 \%$ at SP1. UI was the best predictor of time above mean across all

341 sites (Figure $7 \mathrm{~b}, \mathrm{R}^{2}=0.60, \mathrm{p}=0.005$ ), and $\mathrm{TI}$ also produced a significant, but less explanatory

342 model. In search of secondary controls, no watershed metrics were strongly correlated $(|\mathrm{R}|<$

3430.45 ) with the primary model residuals.

\section{Discussion}

\section{$345 \quad 5.1$ Total imperviousness controls event scale response}

346 At the event scale, TI was the dominant control on a range of hydrologic response metrics at 16

347 sites in Charlotte, NC that spanned a range of imperviousness and mitigation by SCMs.

348 Regression analysis demonstrated that TI was best of a suite of spatially integrated, watershed-

349 scale metrics at describing the variance of storm event runoff ratios. Additionally, a watershed's

350 ability to store small rain events, quantified by a breakpoint in slope between total precipitation 
351 and peak discharge, was also tied best to TI. These results are in alignment with other

352 hydrologic effects of urbanization, including a loss of watershed recharge and storage (Booth

353 2002) and decreased evaporation and transpiration with loss of vegetation (Grimmond and Oke,

354 1999). Lower storage capacity would lead to more frequent flooding events, and therefore alter

355 disturbance regimes in stream ecosystems. Additionally, TI had the strongest statistical control

356 on both the distributions of peak discharge across sites and the rate of response of peak discharge

357 to rainfall once initial storage (i.e., breakpoint) had been exceeded. These results add to an

358 increasing body of evidence of urbanization, measured by TI, causing increased surface runoff

359 and drainage efficiency (Shuster et al 2005). This is also demonstrated by the negative

360 correlation $(\mathrm{R}=-0.75)$ between $\mathrm{TI}$ and each site's coefficient of variation of runoff ratios.

361 Other metrics like UI and tree coverage fraction frequently produced significant linear regression

362 relationships at our study sites, but the strength of these was consistently less than those

363 produced by using TI. Many studies have shown the relationship between hydrologic response

364 and TI (see reviews by Arnold and Gibbons, 1996 and Shuster et al., 2005). However, modeling

365 studies that considered both TI and EI (EI is assumed to be analogous to UI if SCMs operate as

366 designed), found EI to be either a better metric than TI or an important control when modeling

367 hydrologic response to rainfall (Lee and Heaney, 2003; Guo, 2008; Dewals et al., 2012; Shields

368 and Tague, 2014). In the watersheds in our study, TI best explained event scale hydrology across

369 sites, indicating that TI is the single best metric for quantifying impacts of urban development on

370 storm runoff delivered to streams.

\section{$371 \quad 5.2$ Secondary controls on event scale hydrology}

372 An analysis of residuals of the linear models between event hydrologic variables and TI was

373 performed to identify secondary watershed controls. Analogous to the fraction of directly 
374 connected impervious surfaces (e.g., Shuster et al., 2005; Walsh et al., 2005; Shields and Tague,

375 2014), UI/TI was the dominant secondary control of runoff ratios. In our 16 watersheds, the

376 correlation between the residuals and UI/TI was negative, so that for a given TI, runoff ratios

377 decrease as the proportion of untreated impervious increases. Counterintuitively, this suggests

378 that as a higher percentage of TI is treated by SCMs (i.e., UI/TI decreases), runoff ratios actually

379 increase for given a level TI. Actual event runoff ratios were also weakly negatively correlated

380 to UI/TI ( $\mathrm{R}$ ranging from -0.10 to -0.24 across the percentiles). We postulate that this effect is a

381 result of different ages and styles of infrastructure within the SCM catchments than in areas with

382 untreated imperviousness. In areas with high density of SCMs, development is likely newer, with

383 less secondary permeability of pavement (Wiles and Sharp, 2008) and fewer joints and breaks in

384 drainage pipes. Areas with SCMs may also be more likely to have a higher density of drainage

385 pipes and curb and gutter systems, than in areas without SCMs, where informal drainage (e.g.,

386 roads without curbs) may be more prevalent (Walsh et al., 2012). Together or separately, these

387 differences result in greater drainage efficiency of stormwater runoff to SCMs in newer

388 developments, producing the higher runoff ratios observed in this study. The presence of a SCM

389 may even spur greater connectivity of impervious surfaces because of the perception that the

390 SCM will mitigate the effects of the runoff.

391 Although peak discharge did not have a consistent, dominant secondary control across the

392 percentiles considered, watershed area was the most prevalent. The trend, as shown in Figure 4b

393 was that as watershed area increases, the residuals decrease (i.e., peak discharge for a given TI

394 decreases as area increases). This finding is consistent with peak attenuation due to channel and

395 floodplain storage during flood routing (Bedient et al., 2002). It may also be attributable to non-

396 uniform rainfall (both spatially and temporally) in larger watersheds, where isolated convective 
thunderstorms may produce high rain intensities in a small area while the rest of the watershed

398 receives little or no precipitation. This finding contrasts with that of Galster et al. (2006) who

399 observed a positive linear relationship between peak unit discharge and area. Galster et al.

400 (2006) tracked a single event downstream within the channel network and attributed the

401 observed relationship to downstream increases in TI, which does, however, agree with our

402 findings of TI as a primary control. Despite our observed trend of decreasing peak unit

403 discharge residuals with increasing area, in the smallest watersheds $\left(<2 \mathrm{~km}^{2}\right)$ with the highest

404 SCM treatment, the residuals are negative compared to positive residuals in slightly larger

405 watersheds $\left(2-5 \mathrm{~km}^{2}\right)$ with lower SCM treatment. The effects of flood routing and spatial

406 variation in rainfall should be small over this range of scales, so the difference between the

407 highly treated and less treated watersheds implies that SCM mitigation may be a tertiary control

408 on peak discharges across sites.

\section{$409 \quad 5.3$ Tree coverage and SCM mitigation predict annual hydrologic response}

410 While processes associated with impervious coverage were found to dominate the hydrology at

411 the event scale, at the annual scale, tree coverage and stormwater mitigation of impervious

412 surfaces have a larger impact. The water yield fraction across sites was best explained by tree

413 coverage, as a linear relationship showed lower water yield as tree coverage increased (Figure

414 7a). An urban forest canopy can increase transpiration, interception and subsequent evaporation

415 (Nowak and Dwyer, 2007). This is inconsistent with the finding for runoff ratios at the event

416 time scale, which were best explained by TI. TI is approximately the complement of total

417 vegetation (i.e., total vegetation coverage $=$ tree coverage + lawn coverage $\approx 1-\mathrm{TI}$ ). At the

418 event time scale, fresh rainfall is available for transpiration by both shallow-rooted lawns and

419 deep-rooted trees, so TI may best represent plant access to water for transpiration. However, at 
420 longer time scales, tree coverage may better represent vegetative effects on hydrology than TI

421 because trees have deeper rooting systems than grasses that allow them to transpire groundwater

422 between rain events when the water table is lowered. The increased transpiration of urban trees

423 compared to urban grasses was demonstrated by Shields and Tague (2014), where simulations of

424 suburban and urban residential neighborhoods in semiarid Santa Barbara, California showed live

425 oak consistently transpired more water per unit vegetated area than local grasses.

426 We characterized stream flashiness as the fraction of time the hydrologic record spent above its

427 mean discharge. Low values of this metric occur if the flow distribution is skewed up towards

428 fewer, larger events and this is indication of the intensification of the hydrologic response to

429 precipitation. A previous study demonstrated that increased urbanization, as measured by TI,

430 lead to decreases in the time spent above the mean (Booth et al., 2004). In this study, a similar

431 relationship between the time above mean and TI existed, but UI, the fraction of watershed area

432 covered by impervious surfaces not mitigated by SCMs, was a stronger predictor. We attribute

433 this to SCM design, which both delays the release of stored runoff from impervious surfaces and

434 can promote local infiltration and groundwater recharge (Roesner et al., 2001; CMSWS, 2013).

435 Localized infiltration in SCMs can lead to increased baseflow, which causes hydrologic records

436 to spend more time above the mean discharge (Hamel et al., 2013; Bhaskar et al., 2016).

437 However, a vast majority of the SCMs in this study were retention ponds and wetlands which

438 designed with liners to limit infiltration (CMSWS, 2013). Therefore, we attribute this result to

439 attenuation of surface water in SCMs rather than elevated infiltration. Jefferson et al. (2015)

440 used isotopic hydrograph separation to show that SCMs surface outflow contributes

441 disproportionately high amounts of runoff to streamflow during hydrograph recession relative to

442 their drainage area. Our results, in combination with the goals of SCM design and observations 
443 of Jefferson et al. (2015), explain why UI, which implicitly incorporates SCM mitigated

444 impervious surfaces, outperforms TI at predicting stream flashiness because SCMs temporarily

445 retain surface runoff. Together, results of annual hydrologic variables indicate that management

446 strategies like tree planting and mitigating impervious areas can reduce total water runoff and

447 decrease hydrologic record flashiness.

\section{$448 \quad 5.4$ Why was our hypothesis wrong? Highlighting topics for further research}

449 We hypothesized that metrics incorporating both the extent of urban impact and mitigation with

450 stormwater control measures (i.e., UI and MA), would better predict hydrologic variables than

451 those quantifying urbanization or SCM mitigation alone. This hypothesis implied that SCMs are

452 affecting storm event runoff. However, at the event-scale, TI produced the strongest

453 relationships. We propose four possible explanations for these unexpected results: (1) the signal

454 produced by the distribution of SCM mitigation was insufficient to overcome the signal from

455 imperviousness, (2) these metrics do not incorporate necessary information on spatial

456 arrangement of both impervious surfaces and SCMs, (3) TI is actually a better predictor than EI

457 of the suite of hydrologic behaviors studied here and (4) SCMs are unable to reverse the

458 connection between urban surfaces and streams formed by storm drainage pipes (i.e., some

459 mitigated impervious surfaces are still effective). These possible explanations highlight needs

460 for future research.

461 The sixteen sites span a range of urbanization and SCM mitigation that reflects current practices

462 in Charlotte, NC. The population of Charlotte grew by 14\% between 2007 and 2014 (United

463 States Census Bureau, downloaded at: http://factfinder.census.gov/), and this growth has

464 coincided with urban development under stormwater post-construction ordinances implemented

465 in 2007. This extensive, regulated development makes Charlotte a city with a relatively high 
466 level of SCM mitigation. However, while the range of mitigated area at the sites considered in

467 this study is broad, it is skewed toward sites with less mitigation, which may not be sufficient to 468 compensate for the impacts of urbanization at the watershed scale.

469 To investigate the sensitivity of our analyses to the influence of including a single very small, 470 highly mitigated watershed (SL1), we repeated the analysis without SL1. This analysis showed 471 that TI was still the best predictor of the distributions of runoff ratios and peak discharges, the 472 breakpoint in slopes of the relationship of peak discharge vs. $\mathrm{PPT}_{\mathrm{E}}$, and discharge response rates.

473 Similarly, tree coverage remained the best predictor of total water yield. The only result that 474 changed was that TI slightly outperformed UI $\left(\mathrm{R}^{2}=0.58\right.$ and 0.54 , respectively) at predicting the 475 time above mean. Since the results were mostly unchanged, we assert that these 15 sites may not 476 have enough SCM mitigation to override the signal of urbanization. This is similar to results 477 from studies in Cincinnati, $\mathrm{OH}$ on the effects of implementing rain gardens and rain barrels, 478 which are more distributed forms of stormwater management. The authors found that partial 479 mitigation (which reduced EI by 9\%) made small, but detectable changes to hydrology, 480 however, these changes were not enough to effect stream biota (Shuster and Rhea, 2013; Roy et 481 al., 2014).

482 Secondly, while one of the strengths of the metrics we chose is that they are easily computed and 483 readily incorporated into policy, their simplicity renders them blind to spatial arrangement. Our 484 analysis was not able to address proximity of impervious surfaces to one another or to the 485 watershed outlet. In a modeling study, Corbett et al. (1997) found that although clustering 486 impervious surfaces did not change event-scale rainfall-runoff ratios compared to scenarios with 487 distributed impervious surfaces, it did increase peak flows. Other modeling study showed that 488 runoff volumes increased (Zhang and Shuster, 2014) and peak discharge decreased (Yang et al., 
2011) as the average hydrologic distance between impervious areas and the outlet decreased.

490 These studies highlight complexity of the interaction between impervious area distribution and

491 stormwater hydrology. Similar information is lacking with regard to the location of SCMs that

492 could also have significant effects on runoff timing and volume. At four sites in the Mid-

493 Atlantic United States, Loperfido et al. (2014) showed that many small, distributed SCMs

494 increased baseflow, increased precipitation-peak discharge breakpoints, and decreased extreme

495 event runoff volumes more than a site with larger, more centralized SCMs. This shows that

496 metrics like TI, UI, and MA may be missing important information about the spatial arrangement

497 of both urban surfaces and SCMs.

498 Our hypotheses may also have been incorrect because one of two assumptions made in our

499 theoretical framework was invalid. The first assumption was that EI is a better predictor of

500 urban event scale hydrologic response than TI because it accounts for both impervious surfaces

501 and their connectivity. There is a strong theoretical basis for EI as a predictor of urban

502 hydrologic response (Shuster et al., 2005), and numerous modeling (Lee and Heaney, 2003; Guo,

503 2008; Dewals et al., 2012; Shields and Tague, 2014) and ecological studies (Walsh et al., 2005;

504 Walsh and Kunapo, 2009) have demonstrated the importance of including connectivity.

505 However, no empirical studies known to the authors have actually demonstrated the predictive

506 power of EI with respect to hydrologic response.

507 The second assumption is that because SCMs are designed to replicate the hydrology in an

508 undeveloped watershed (i.e., meet pre-development conditions), mitigated impervious surfaces

509 are no longer directly connected and therefore not effective (suggested by Walsh et al. (2005)).

510 However, this assertion requires that SCM design standards address all of the changes to flow

511 regimes from urbanization, which some argue is not the case in practice (e.g., Burns et al., 2012; 
512 Askarizadeh et al., 2015). Additionally, the performance of a SCM may vary based on SCM

513 type, design approach, age or a combination of these factors. For example, in-line ponds may

514 provide flow control and water quality benefits for smaller events, but larger events or events in

515 wet antecedent conditions pass through with little retention. Because these ponds are directly on

516 the stream network, they typically mitigate much larger areas than those closer to the ridgeline.

517 This is further complicated because policies that specify SCM design, and therefore

518 performance, vary both across political districts and in the same district through time. If in-line

519 ponds or other SCMs underperform, this will lead to a misrepresentation of metrics like MA, UI

520 and EI. The opposite effect may also be true: in-line ponds that we have ignored from our

521 analysis, along with SCM approaches that provide small amounts of storage such as swales and

522 infiltration trenches, may be affecting the hydrological signal. A potential improvement to these

523 problems is to base the metrics of SCM mitigation on their performance or quality. However,

524 quantifying "quality" in the face of varying design standards and watersheds is challenging.

525 Indeed, this variability of performance is demonstrated by the wide range of volume reduction

526 reported by the International Stormwater Best Management Practice Database (Geosyntec

527 Consultants and Wright Water Engineers, 2011). Finally, it is possible that the effects of a fully

528 functioning SCM on local hydrology do not translate to the watershed scale where multiple

529 SCMs influence streamflow at different times.

\section{Conclusions and Implications}

531 The purpose of this study was to test whether or not watershed metrics characterizing both urban

532 development and mitigation with SCM were better able to explain variation in hydrology across

533 sites than those quantifying urbanization or mitigation alone. We analyzed hydrologic regimes

534 for 16 urban watersheds with stormwater control measures in Charlotte, NC. Total 
535 imperviousness, a metric characterizing only urbanization with no information about SCMs, was

536 the best predictor of storm event hydrologic variables including rainfall runoff ratios, peak

537 discharge, the ability of watersheds to buffer small rain events, and the rate of response between

538 peak discharge and precipitation once that buffering capacity has been exceeded. Watershed

539 metrics that included SCM mitigation were only found to be secondary or tertiary controls on

540 hydrologic behavior at the event scale. These data indicate that SCMs implemented at the levels

541 observed are not significantly affecting event hydrology at the watershed scale.

542 Annual hydrologic behavior, however, was best correlated to metrics other than TI. The total

543 water yield was best related to the fraction of tree coverage, potentially because trees can

544 transpire deeper groundwater between rain events. The time the discharge record spent above

545 mean, a measurement of streamflow flashiness, was best related to unmitigated impervious area,

546 indicating that SCMs may affect baseflow recession at time scales longer than a single event, as

547 defined in this study.

548 Despite intense efforts to mitigate stormwater runoff through SCMs in newly developed areas

549 and opportunistically through retrofits in older developments, our analysis demonstrates that

550 these investments have not paid off in terms of storm event scale hydrologic response at the

551 watershed scale. Therefore, unless different results are produced by future empirical studies

552 either at sites with a broader range of SCM mitigation (e.g., 20-80\%) or that incorporate SCM

553 performance, TI is the watershed metric that policy makers should use to manage watersheds to

554 mitigate impacts to streams. Tree planting may be a desirable management strategy for reducing

555 total runoff, while SCM mitigation of impervious surfaces is a strategy that may reduce

556 hydrologic flashiness on longer time scales by extending baseflow recession. 


\section{$557 \quad 7$ Acknowledgements}

558 This research is based upon work supported by the National Science Foundation under Grant No.

559 CBET-1034043. We also acknowledge the support of USDA/NIFA S-1063. The authors would

560 also like to thank Charlotte-Mecklenburg Stormwater Services, specifically Kyle Hall, Michael

561 MacIntyre, and Jordan Miller. Dr. Craig Allan, UNC Charlotte, provided logistical, technical and

562 instrumentation support. Additionally, we give appreciation to Dr. Christina Tague, Alea Tuttle,

563 Mackenzie Osypian, Perry Isner, Ralph McGee, Xueying Wang, and Erin Looper for their help

564 at the drawing board, in the field and in the laboratory. Finally, we thank the University of North

565 Carolina at Charlotte, Purdue University and Kent State University for keeping our lab benches

566 lit and our computers connected to the body of knowledge upon which this work seeks to

567 expand. Data collected by the authors used in this analysis is hosted on the Purdue University

568 Research Repository. 


\section{References}

570

571

572

573

574

575

576

577

578

579

580

581

582

583

584

585

586

587

588

589

590

591

592

593

594

595

596

597

598

599

600

601

602

603

604

605

606

607

608

609

610

611

612

Allan, C.J., Diemer, J.A., Gagrani, V., 2013. Beaverdam Creek Watershed Monitoring Report 2005-2012, Charlotte, NC.

Alley, W., Veenhuis, J., 1983. Effective Impervious Area in Urban Runoff Modeling. J. Hydraul. Eng.-ASCE, 109(2): 313-319.

Alley, W.M., Schaake, J.C., Dawdy, D.R., 1980. Parametric-deterministic urban watershed model. J. Hydr. Eng. Div.-ASCE, 106(5): 679-690.

Arnold, C.L., Gibbons, C.J., 1996. Impervious surface coverage: the emergence of a key environmental indicator. J. Am. Plann. Assoc., 62(2): 243-258.

Askarizadeh, A. et al., 2015. From Rain Tanks to Catchments: Use of Low-Impact Development To Address Hydrologic Symptoms of the Urban Stream Syndrome. Envir. Sci. Tech. Lib., 49(19): 11264-11280.

Bedient, P.B., Huber, W.C., Vieux, B.E., 2002. Hydrology and floodplain analysis. PrenticeHall, Inc., NJ.

Bhaskar, A.S. et al., 2016. Will it rise or will it fall? Managing the complex effects of urbanization on base flow. Freshwater Science, 35(1): 293-310.

Booth, D.B., Hartley, D., Jackson, R., 2002. Forest cover, impervious-surface area, and the mitigation of stormwater impacts. J. Am. Water Resour. Assoc. (JAWRA), 38(3): 835845.

Booth, D.B. et al., 2004. Reviving urban streams: Land use, hydrology, biology, and human behavior. J. Am. Water Resour. Assoc. (JAWRA), 40(5): 1351-1364.

Burns, M.J., Fletcher, T.D., Walsh, C.J., Ladson, A.R., Hatt, B.E., 2012. Hydrologic shortcomings of conventional urban stormwater management and opportunities for reform. Landsc. Urban Plan., 105(3): 230-240.

Burns, M.J., Walsh, C.J., Fletcher, T.D., Ladson, A.R., Hatt, B.E., 2015. A landscape measure of urban stormwater runoff effects is a better predictor of stream condition than a suite of hydrologic factors. Ecohydrology, 8(1): 160-171.

Cassin, J. et al., 2005. Development of hydrological and biological indicators o flow alteration in Puget Sound Lowland streams. King County DNRP, Seattle, WA.

CMSWS, C.-M.S.W.S., 2013. Charlotte-Mecklenburg BMP Design Manual (Revised Edition).

Corbett, C.W., Wahl, M., Porter, D.E., Edwards, D., Moise, C., 1997. Nonpoint source runoff modeling A comparison of a forested watershed and an urban watershed on the South Carolina coast. J. Exp. Mar. Biol. Ecol., 213(1): 133-149.

Dewals, B.J., Archambeau, P., Khuat Duy, B., Erpicum, S., Pirotton, M., 2012. Semi-Explicit Modelling of Watersheds with Urban Drainage Systems. Eng. Appl. Comp. Fluid, 6(1): 46-57.

Eckhardt, K., 2005. How to construct recursive digital filters for baseflow separation. Hydrolog. Process., 19(2): 507-515.

Espey, W.H., Morgan, C.W., Masch, F.D., 1966. A study of some effects of urbanization on storm runoff from a small watershed. Texas University at Austin, Center for Research in Water Resources.

Gagrani, V., Diemer, J.A., Karl, J.J., Allan, C.J., 2014. Assessing the hydrologic and water quality benefits of a network of stormwater control measures in a SE U.S. Piedmont watershed. J. Am. Water Resour. Assoc. (JAWRA), 50(1): 128-142. 
Galster, J.C. et al., 2006. Effects of urbanization on watershed hydrology: The scaling of discharge with drainage area. Geology, 34(9): 713-716.

Geosyntec Consultants, I., Wright Water Engineers, I., 2011. International Stormwater Best Management Practices (BMP) Database Technical Summary: Volume Reduction.

Google, I., 2015. Google Earth, Mountain View, CA.

Grimmond, C., Oke, T., 1999. Evapotranspiration rates in urban areas. Int. Assoc. Hydrolog. Sci. (IAHS), 259: 235-244.

Guo, J., 2008. Volume-Based Imperviousness for Storm Water Designs. J. Irrig. Drain. E.ASCE, 134(2): 193-196.

Hamel, P., Daly, E., Fletcher, T.D., 2013. Source-control stormwater management for mitigating the impacts of urbanisation on baseflow: A review. J Hydrol, 485: 201-211.

Hood, M.J., Clausen, J.C., Warner, G.S., 2007. Comparison of Stormwater Lag Times for Low Impact and Traditional Residential Development. J. Am. Water Resour. Assoc. (JAWRA), 43(4): 1036-1046.

Horner, R., Lim, H., Burges, S., 2001. Hydrologic monitoring of the Seattle ultra-urban stormwater management projects. Water Resources Series, Technical Report no. 170.

Hur, J. et al., 2008. Does current management of storm water runoff adequately protect water resources in developing catchments? J. Soil and Water Conserv., 63(2): 77-90.

Jarden, K.M., Jefferson, A.J., Grieser, J.M., 2015. Assessing the effects of catchment-scale urban green infrastructure retrofits on hydrograph characteristics. Hydrolog. Process. (In Press).

Jefferson, A., Bell, C.D., Clinton, S., McMillan, S., 2015. Application of isotope hydrograph separation to understand contributions of stormwater control measures to urban headwater streams. Hydrolog. Process. (In Press).

Lee, J.G., Heaney, J.P., 2003. Estimation of Urban Imperviousness and its Impacts on Storm Water Systems. J. Water Res. Pl.-ASCE, 129(5): 419-426.

Leopold, L.B., 1968. Hydrology for urban land planning: A guidebook on the hydrologic effects of urban land use. USGS Circular 554.

Loperfido, J.V., Noe, G.B., Jarnagin, S.T., Hogan, D.M., 2014. Effects of distributed and centralized stormwater best management practices and land cover on urban stream hydrology at the catchment scale. J. Hydrol., 519, Part C(0): 2584-2595.

Lyne, V., Hollick, M., 1979. Stochastic time-variable rainfall-runoff modelling, Institute of Engineers Australia National Conference, pp. 89-93.

May, C.W., Horner, R.R., Karr, J.R., Mar, B.W., Welch, E.B., 1997. Effects of urbanization on small streams in the Puget Sound ecoregion. Watershed Prot. Tech., 2(4): 483-494.

Nowak, D., Dwyer, J., 2007. Understanding the Benefits and Costs of Urban Forest Ecosystems. In: Kuser, J. (Ed.), Urban and Community Forestry in the Northeast. Springer Netherlands, pp. 25-46.

NRC, 2008. Urban stormwater management in the United States. National Academies Press, Washington D. C.

O’Driscoll, M., Clinton, S., Jefferson, A., Manda, A., McMillan, S., 2010. Urbanization effects on watershed hydrology and in-stream processes in the Southern United States. Water, 2(3): 605-648.

Paul, M.J., Meyer, J.L., 2001. Streams in the urban landscape. Urban Ecol.: 207-231.

Pitt, R., Chen, S., Clark, S., Swenson, J., Ong, C., 2008. Compaction's Impacts on Urban StormWater Infiltration. J. Irrig. Drain. E.-ASCE, 134(5): 652-658. 
R Core Team, 2013. R: A language and environment for statistical computing. R Foundation for Statistical Computing, Vienna, Austria.

Robbins, P., Birkenholtz, T., 2003. Turfgrass revolution: measuring the expansion of the American lawn. Land Use Policy, 20(2): 181-194.

Roesner, L., Bledsoe, B., Brashear, R., 2001. Are best-management-practice criteria really environmentally friendly? J. Water Res. Pl.-ASCE, 127(3): 150-154.

Roy, A.H. et al., 2014. How Much Is Enough? Minimal Responses of Water Quality and Stream Biota to Partial Retrofit Stormwater Management in a Suburban Neighborhood. PLoS ONE, 9(1): e85011.

Roy, A.H. et al., 2008. Impediments and solutions to sustainable, watershed-scale urban stormwater management: Lessons from Australia and the United States. Environ. Manage., 42(2): 344-359.

Schueler, T.R., 1995. The importance of imperviousness. Watershed Prot. Tech., 1(3): 100-111.

Shields, C., Tague, C., 2014. Ecohydrology in semiarid urban ecosystems: Modeling the relationship between connected impervious area and ecosystem productivity. Water Resour. Res., 51(1):302-319

Shuster, W., Rhea, L., 2013. Catchment-scale hydrologic implications of parcel-level stormwater management (Ohio USA). J. Hydrol., 485: 177-187.

Shuster, W.D., Bonta, J., Thurston, H., Warnemuende, E., Smith, D.R., 2005. Impacts of impervious surface on watershed hydrology: A review. Urban Water J., 2(4): 263-275.

State Climate Office of North Carolina, 2013. CRONOS.

Thiessen, A.H., 1911. Precipitation averages For large areas. Monthly Weather Review, 39(7): 1082-1089.

United States Census Bureau, 2015. American Fact Finer, downloaded at: http://factfinder.census.gov/

USGS, 1982. Measurement and computation of streamflow: Volume 1. Measurement of stage and discharge. US Geological Survey water supply paper, 2175: 1-284.

Villarreal, E.L., Semadeni-Davies, A., Bengtsson, L., 2004. Inner city stormwater control using a combination of best management practices. Ecol.Eng., 22(4-5): 279-298.

Walsh, C.J., Fletcher, T.D., Burns, M.J., 2012. Urban Stormwater Runoff: A New Class of Environmental Flow Problem. PLoS ONE, 7(9): e45814.

Walsh, C.J., Fletcher, T.D., Ladson, A.R., 2005. Stream restoration in urban catchments through redesigning stormwater systems: looking to the catchment to save the stream. J. N. Am. Benthol. Soc., 24(3): 690-705.

Walsh, C.J., Kunapo, J., 2009. The importance of upland flow paths in determining urban effects on stream ecosystems. J. N. Am. Benthol. Soc., 28(4): 977-990.

Wiles, T.J., Sharp, J.M., 2008. The Secondary Permeability of Impervious Cover. Environ. Eng. Geosci., 14(4): 251-265.

Yang, G.X., Bowling, L.C., Cherkauer, K.A., Pijanowski, B.C., 2011. The impact of urban development on hydrologic regime from catchment to basin scales. Landsc. Urban Plan., 103(2): 237-247

Zhang, Y., Shuster, W., 2014. Impacts of Spatial Distribution of Impervious Areas on Runoff Response of Hillslope Catchments: Simulation Study. J. Hydraul. Eng.-ASCE, 19(6): 1089-1100. 
704 Table 1: Extent of urban development and SCM mitigation for the 16 analyzed watersheds.

\begin{tabular}{|c|c|c|c|c|c|c|c|c|c|}
\hline USGS ID & Site Name & $\begin{array}{c}\text { Drainage } \\
\text { Area } \\
\left(\mathrm{km}^{2}\right)\end{array}$ & $\begin{array}{c}\text { Total } \\
\text { Imperviousness } \\
\text { (TI) }[\%]\end{array}$ & $\begin{array}{c}\text { Effective } \\
\text { Imperviousness } \\
\text { (EI) }[\%]\end{array}$ & $\begin{array}{c}\text { Untreated } \\
\text { Imperviousness } \\
\text { (UI) [\%] }\end{array}$ & $\begin{array}{c}\text { Unmitigated } \\
\text { Impervious } \\
\text { Fraction } \\
\text { (UI/TI) [\%] }\end{array}$ & $\begin{array}{c}\text { Mitigated } \\
\text { Area (MA) } \\
{[\%]}\end{array}$ & $\begin{array}{c}\text { SCM } \\
\text { Density } \\
{\left[/ \mathrm{km}^{2}\right]} \\
\end{array}$ & $\begin{array}{c}\text { Tree } \\
\text { Coverage } \\
{[\%]}\end{array}$ \\
\hline-- & SL1 & 0.15 & 24 & 0.2 & 0.48 & 2.0 & 89 & 20.4 & 16 \\
\hline-- & SP1 & 1.01 & 14 & 5.4 & 7.4 & 53 & 16 & 2.0 & 49 \\
\hline-- & UL1 & 1.44 & 43 & 28 & 41 & 95 & 16 & 3.5 & 41 \\
\hline-- & UP1 & 1.45 & 27 & 7.7 & 12 & 44 & 48 & 3.4 & 59 \\
\hline 214643820 & Edwards Branch & 2.51 & 43 & -- & 29 & 67 & 28 & 2.0 & 45 \\
\hline 214645080 & Briar Creek Trib. & 3.11 & 32 & -- & 31 & 97 & 1.3 & 0.96 & 56 \\
\hline 2146470 & Little Hope Creek & 6.81 & 42 & -- & 39 & 93 & 5.5 & 1.5 & 50 \\
\hline 214297160 & Beaverdam Creek & 9.62 & 8.6 & -- & 6.9 & 80 & 4.0 & 1.2 & 66 \\
\hline 214266080 & Gar Creek & 9.79 & 4.1 & -- & 4.0 & 98 & 1.3 & 0.10 & 67 \\
\hline 214642825 & Briar Creek & 13.4 & 34 & -- & 31 & 91 & 5.8 & 2.2 & 40 \\
\hline 2142914 & Gum Branch & 13.9 & 23 & -- & 20 & 87 & 10 & 1.9 & 50 \\
\hline 2146315 & Taggart Creek & 14.0 & 37 & -- & 30 & 81 & 12 & 2.9 & 46 \\
\hline 2146562 & Campbell Creek & 14.7 & 37 & -- & 29 & 78 & 17 & 2.6 & 49 \\
\hline 2146211 & Irwin Creek & 15.4 & 32 & -- & 27 & 84 & 9.0 & 2.1 & 47 \\
\hline 2146409 & Little Sugar Creek & 31.5 & 54 & -- & 52 & 96 & 3.2 & 1.5 & 36 \\
\hline 212430293 & Reedy Creek & 32.8 & 12 & -- & 11 & 92 & 2.9 & 0.73 & 61 \\
\hline
\end{tabular}


Table 2: Separated into three sections by horizontal bars. The top section contains the abbreviations and computation methods of the metrics used to characterize the extent of urban

707 development and SCM mitigation in the 16 watersheds. The middle section contains

708 abbreviations and descriptions of the precipitation metrics used in the hydrologic analysis. The

709 bottom section lists the hydrologic variables chosen to characterize each site's hydrologic regime

710 at the event and annual time scales.

\begin{tabular}{|c|c|c|}
\hline Abbreviation/Name & Metric & Unit \\
\hline \multicolumn{3}{|c|}{ Watershed Characteristics } \\
\hline Area & Total watershed area & $\mathrm{km}^{2}$ \\
\hline TI & Total imperviousness (total impervious area / total area) & $\%$ \\
\hline UI & Unmitigated imperviousness [(TI - Mitigated impervious area) / total area] & $\%$ \\
\hline EI & Effective imperviousness (directly connected impervious area/ total area) & $\%$ \\
\hline $\mathrm{UI} / \mathrm{TI}$ & Fraction of impervious area unmitigated (UI/TI) & $\%$ \\
\hline MA & Mitigated Area (SCM mitigated area / total area) & $\%$ \\
\hline SCM Density & (Total number of SCMs in the watershed / total area) & $\mathrm{SCMs} \mathrm{km}^{-2}$ \\
\hline Tree Coverage & Fraction of watershed covered by trees (forested area / total area) & $\%$ \\
\hline \multicolumn{3}{|c|}{ Precipitation Magnitude and Intensity } \\
\hline $\mathrm{PPT}_{\mathrm{E}}$ & Total event precipitation & $\mathrm{mm}$ \\
\hline $\mathrm{I}_{15}$ & Maximum fifteen-minute precipitation intensity & $\mathrm{mm} \mathrm{hr^{-1 }}$ \\
\hline $\mathrm{I}_{60}$ & Maximum sixty-minute precipitation intensity & $\mathrm{mm} \mathrm{hr}^{-1}$ \\
\hline \multicolumn{3}{|c|}{ Storm Event Hydrologic Variables } \\
\hline Runoff ratio & Fraction of rainfall runoff during an event (quick-flow runoff volume / $\mathrm{PPT}_{\mathrm{E}}$ ) & unitless \\
\hline Peak discharge & Maximum instantaneous unit discharge during each event & $\mathrm{m}^{3} \mathrm{~km}^{-2} \mathrm{~s}^{-1}$ \\
\hline & Peak Flow Response to Precipitation & \\
\hline Peak response rate & Slope of linear model between the logarithm of peak discharge vs. $I_{60}$ & $\mathrm{~m}^{3} \mathrm{~km}^{-2} \mathrm{~s}^{-1} / \mathrm{mm} \mathrm{hr}^{-1}$ \\
\hline Breakpoint & $\mathrm{PPT}_{\mathrm{E}}$ value where there is a break in slope between peak discharge and $\mathrm{PPT}_{\mathrm{E}}$ & $\mathrm{mm}$ \\
\hline \multicolumn{3}{|c|}{ Annual Hydrologic Variables } \\
\hline Water yield & Annual fraction of precipitation leaving watershed as streamflow & $\mathrm{mm} / \mathrm{mm}$ \\
\hline Time above mean & Percentage of time discharge was above mean annual discharge & $\%$ \\
\hline
\end{tabular}


712 Table 3: Correlation matrix of 8 site metrics considered in this analysis. Values in the table are

713 Pearson's product moment correlation coefficient (R). EI correlations are only for the four

714 highly treated sites, while the rest are for all 16 sites.

\begin{tabular}{ccccccccc}
\hline & Area & TI & UI & EI* & MA & Tree Coverage & SCM Density & UI/TI \\
\hline Area & 1.00 & 0.07 & 0.27 & 0.64 & -0.48 & 0.12 & -0.34 & 0.49 \\
TI & 0.07 & 1.00 & 0.91 & 0.87 & -0.01 & -0.51 & -0.01 & 0.18 \\
UI & 0.27 & 0.91 & 1.00 & 1.00 & -0.41 & -0.23 & -0.34 & 0.56 \\
EI* & 0.64 & 0.87 & 1.00 & 1.00 & -0.65 & 0.24 & -0.51 & 0.93 \\
MA & -0.48 & -0.01 & -0.41 & -0.65 & 1.00 & -0.63 & 0.91 & -0.94 \\
Tree Coverage & 0.12 & -0.51 & -0.23 & 0.24 & -0.63 & 1.00 & -0.76 & 0.52 \\
SCM Density & -0.34 & -0.01 & -0.34 & -0.51 & 0.91 & -0.76 & 1.00 & -0.82 \\
UI/TI & 0.49 & 0.18 & 0.56 & 0.93 & -0.94 & 0.52 & -0.82 & 1.00 \\
\hline
\end{tabular}

715 
716 Table 4: Best linear models for predicting the $10^{\text {th }}, 30^{\text {th }}, 50^{\text {th }}, 70^{\text {th }}, 90^{\text {th }}$ and $99^{\text {th }}$ percentile

717 rainfall-runoff ratios and peak unit discharge (log-transformed) using only a single site metric.

718 Only significant models $(\mathrm{p}<0.05)$ with the highest $\mathrm{R}^{2}$ are reported. This table describes the linear

719 models shown in Figures 2(a) and 3(a).

\begin{tabular}{ccccccc}
\hline Percentile & \multicolumn{3}{c}{ Rainfall-runoff ratio } & \multicolumn{3}{c}{ Peak unit discharge } \\
& Metric & $\mathrm{R}^{2}$ & Slope & Metric & $\mathrm{R}^{2}$ & Slope \\
\hline 10 & TI & 0.76 & 0.32 & TI & 0.76 & 7.8 \\
30 & TI & 0.75 & 0.41 & TI & 0.83 & 7.8 \\
50 & TI & 0.74 & 0.47 & TI & 0.87 & 8.1 \\
70 & TI & 0.72 & 0.51 & TI & 0.82 & 7.3 \\
90 & TI & 0.43 & 0.43 & TI & 0.63 & 5.8 \\
99 & -- & -- & -- & TI & 0.45 & 5.6 \\
\hline
\end{tabular}

720 
1 Figure Captions: Hydrologic response to stormwater control measures in urban

2 watersheds

3 Colin D. BelI ${ }^{1}$, Sara K. McMillan ${ }^{1}$, Sandra M. Clinton ${ }^{2}$ and Anne J. Jefferson ${ }^{3}$

1. Department of Agricultural and Biological Engineering, Purdue University, 225 S. University Street, West Lafayette, IN 47907, USA

2. Department of Geography and Earth Sciences, University of North Carolina at Charlotte, 9201 University City Boulevard, Charlotte, NC 28223, USA

3. Department of Geology, Kent State University, 221 McGilvrey Hall, Kent, OH 44242, USA

10 Keywords: stormwater management; urban hydrology; impervious surfaces; runoff mitigation;

11 best management practices

\section{Figure Captions}

13 Figure 1: Map of 16 watersheds analyzed in the Charlotte, NC region. The dense cluster of

14 impervious area in the southern portion of the Little Sugar Creek watershed is the city center.

15 Figure 2: Example of modification to Hewlett and Hibbert (1967) constant line separation 16 method used to define the beginning and end of storm events storm events, and to separate

17 stormflow from baseflow for runoff ratio calculation. Example shown is for the first hydrologic

18 events of the 2012 calendar year from Little Sugar Creek.

19 Figure 3: Panel (a) plots all observations of event rainfall-runoff ratios vs. TI. The solid lines

20 represent significant linear relationships at selected percentiles, indicated by the color in the

21 legend. Panel (b) shows the residuals of each of the linear models in (a) vs. the percentage of 
22 unmitigated impervious area. Generally, sites with less mitigated imperviousness have a higher

23 runoff ratio, after discounting the effect of total TI.

24 Figure 4: Panel (a) plots all observations of event peak unit discharge vs. TI. The solid lines are 25 significant linear relationships at selected percentiles, indicated by the color in the legend. Panel

26 (b) shows the residuals of all of the linear models in (a) vs. watershed area. The residuals of the

$2710^{\text {th }}-50^{\text {th }}$ percentiles were most strongly correlated to watershed area. Generally, the residuals

28 decrease as watershed area increases, however the smallest sites deviate from this trend. Panel

29 (c) shows the residuals of the $70^{\text {th }}$ and $90^{\text {th }}$ percentile linear model vs. SCM density, as this

30 produced strongest correlation, although it was heavily leveraged by one site. Panel (d) shows

31 the residuals of the $99^{\text {th }}$ percentile model vs. tree cover, which produced the strongest correlation.

32 Figure 5: Peak discharge response rate vs. TI. This value was computed as the slope of a linear

33 model constructed between peak discharge and maximum 60-minute rainfall intensity at each

34 site. This plot shows that the sensitivity of peak discharge to equivalent forcing from

35 precipitation increases as TI increases $\left(\mathrm{R}^{2}=0.53 \mathrm{p}=0.001\right)$.

36
Figure 6: Panels (a) and (b) give examples of breaks in the slope of log-transformed peak discharge vs. log-transformed $\mathrm{PPT}_{\mathrm{E}}$ at the lowest TI site, Gar Creek (a), and highest TI site, Little Sugar Creek (b). The dashed, vertical lines run through the breakpoints for clarity. Panel (c) shows that as TI increases, the breakpoints decrease indicating a more sensitive response to rainfall and therefore a loss in watershed storage. Different symbols are used to show different levels of statistical significance, and sites with $p>0.20$ are plotted as open circles near the $x$-axis to indicate no change in slope, and therefore no storage. The point for UL1 is left hollow despite 
44 being significant $(\alpha<0.15)$ because the slope decreases at this breakpoint at this site, rather than 45 increases.

46 Figure 7: (a) Annual water yield fraction decreased with increased tree coverage $\left(R^{2}=0.52, p=\right.$

47 0.002), and (b) time above mean decreased with increased UI $\left(R^{2}=0.60, p<0.001\right)$. 


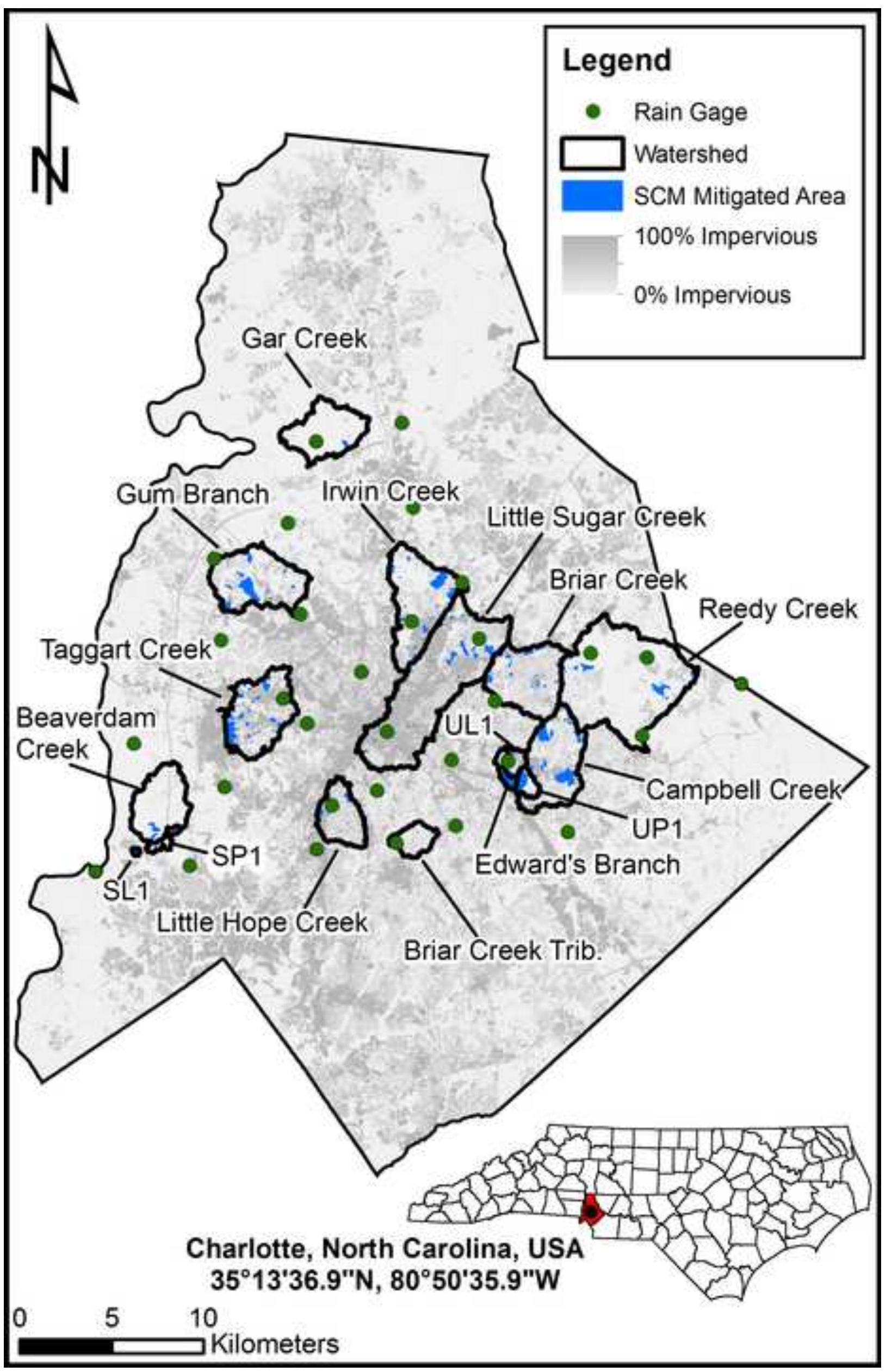




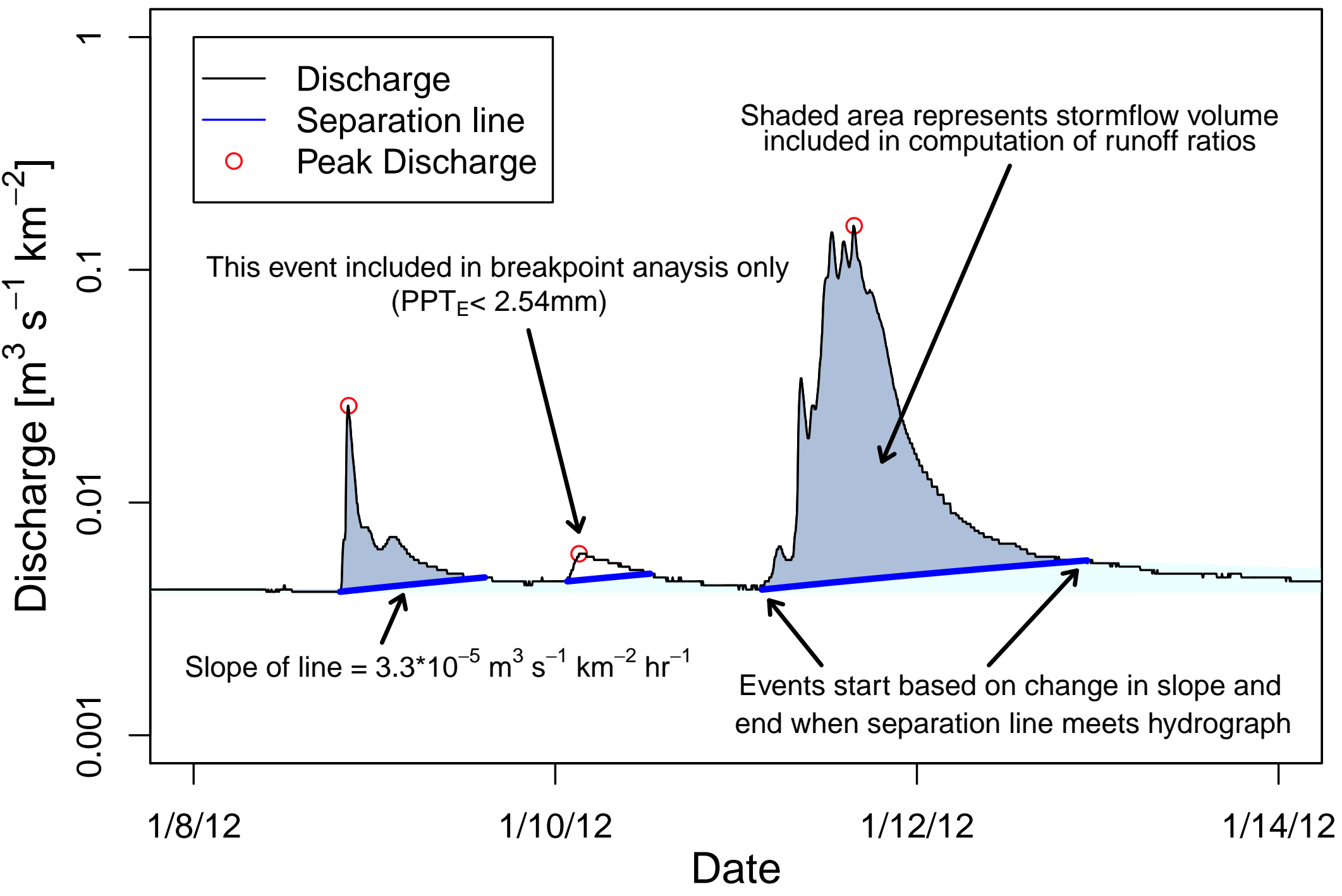


Figure3

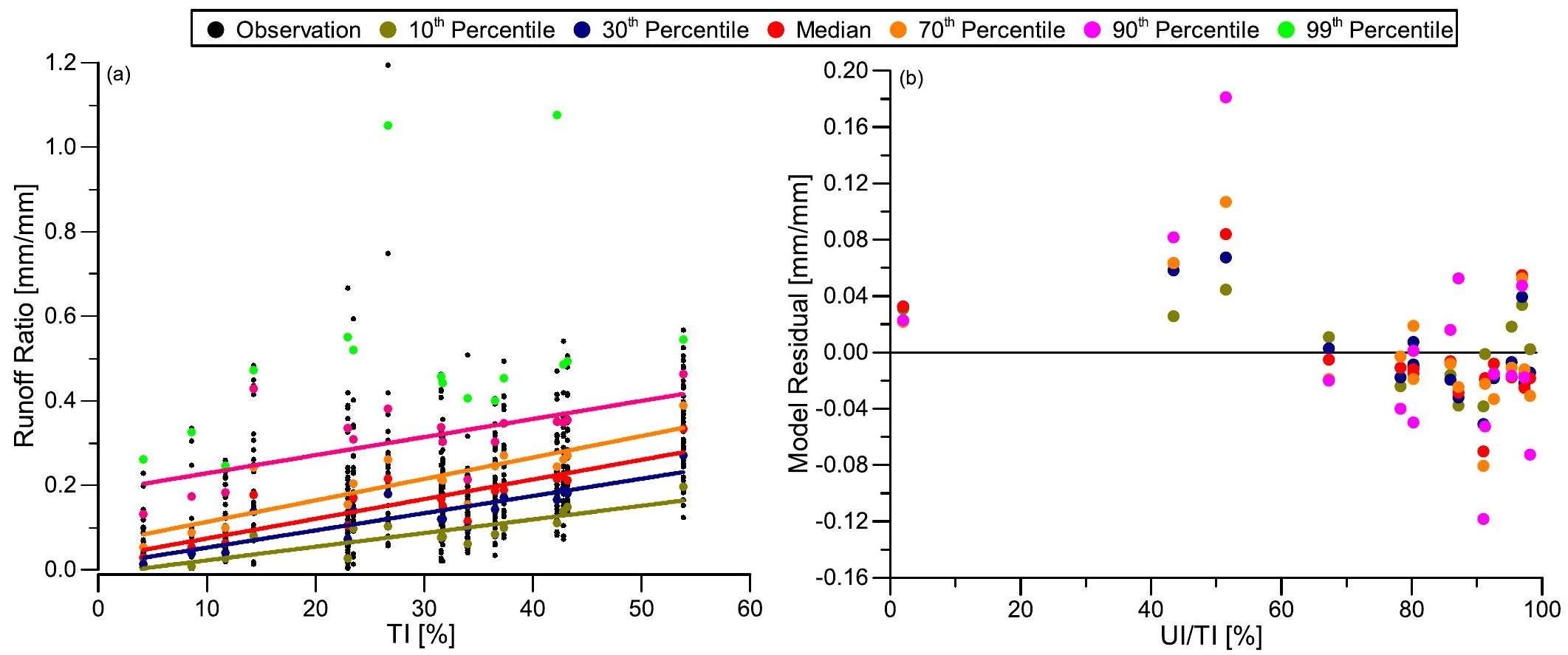




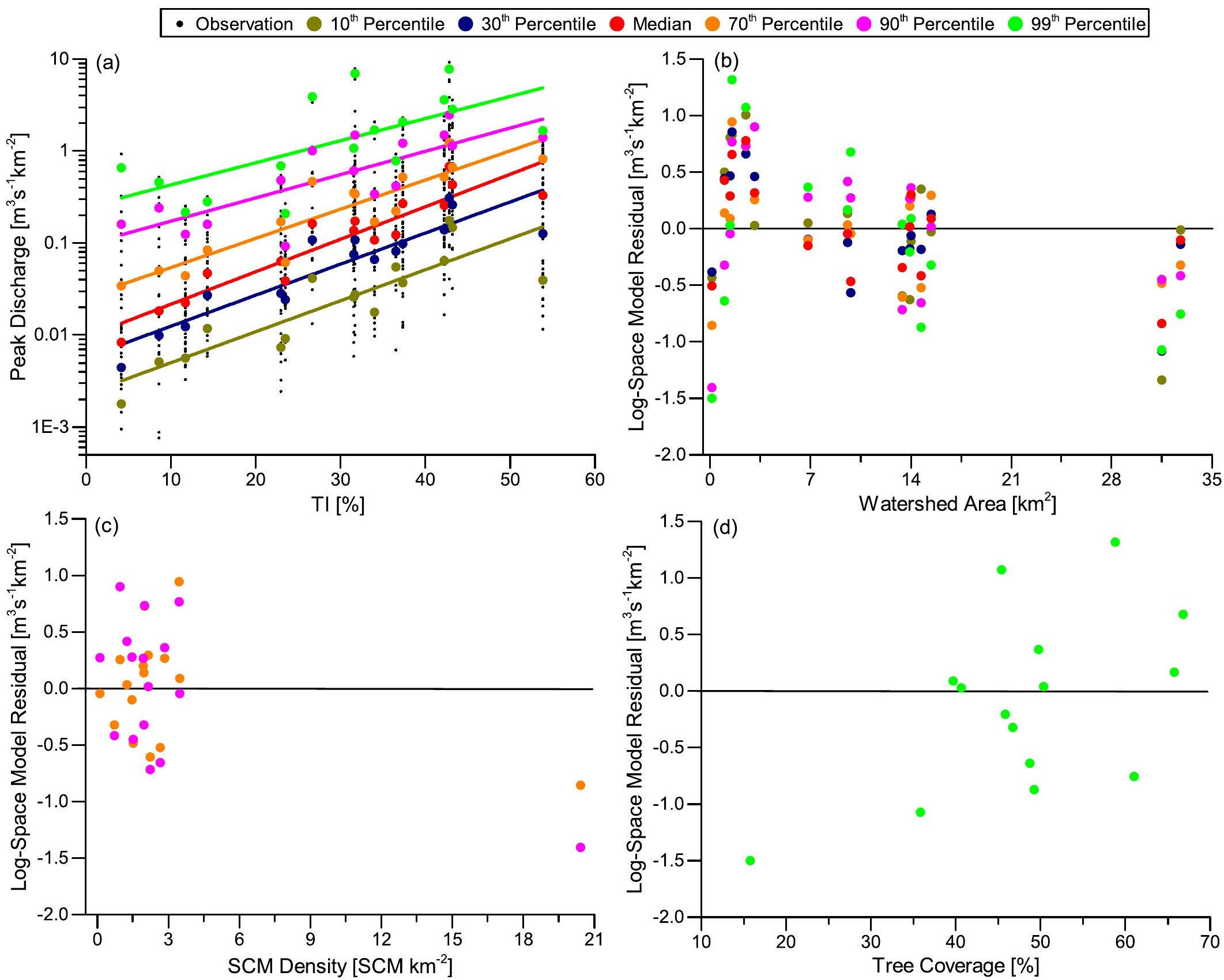



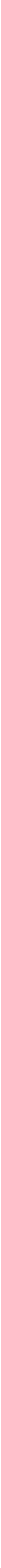

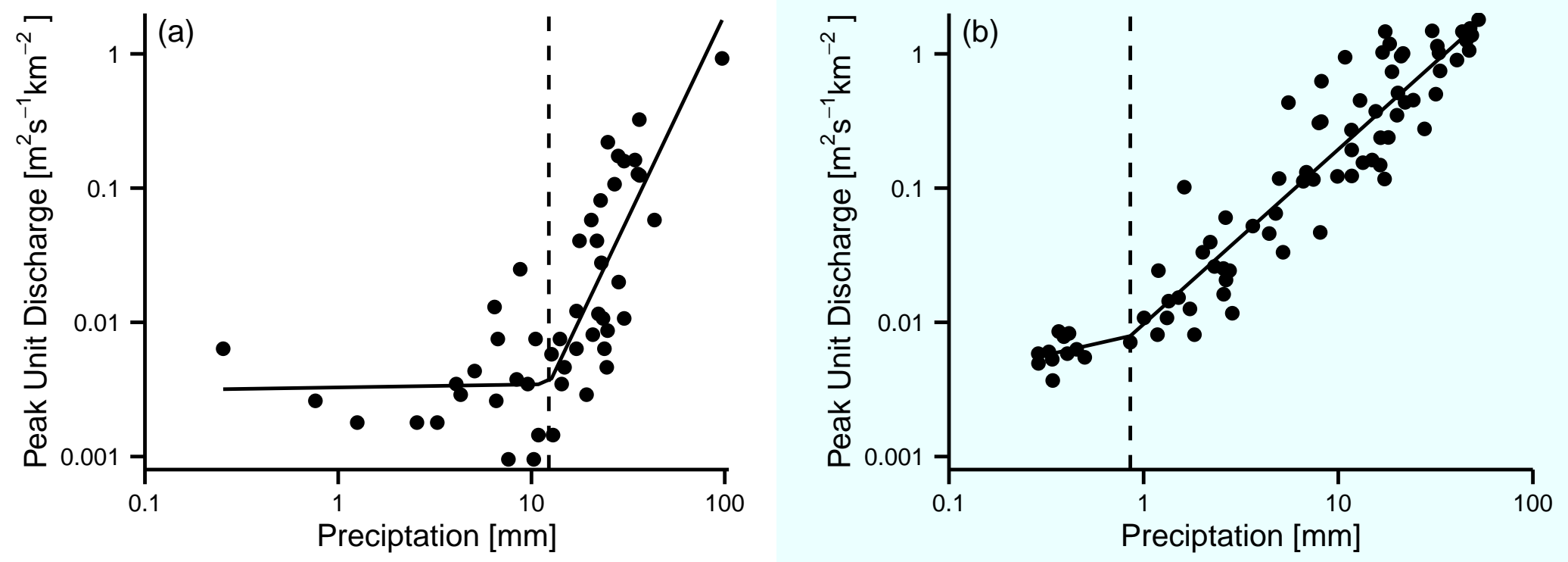

है

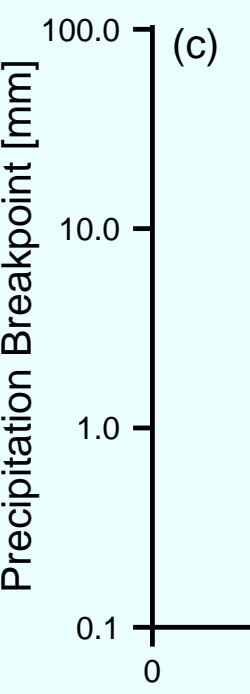

Significance:

$p<0.05$

- $p<0.10$

$\Delta \quad p<0.15$

- $p<0.20 \bigcirc p>0.20$
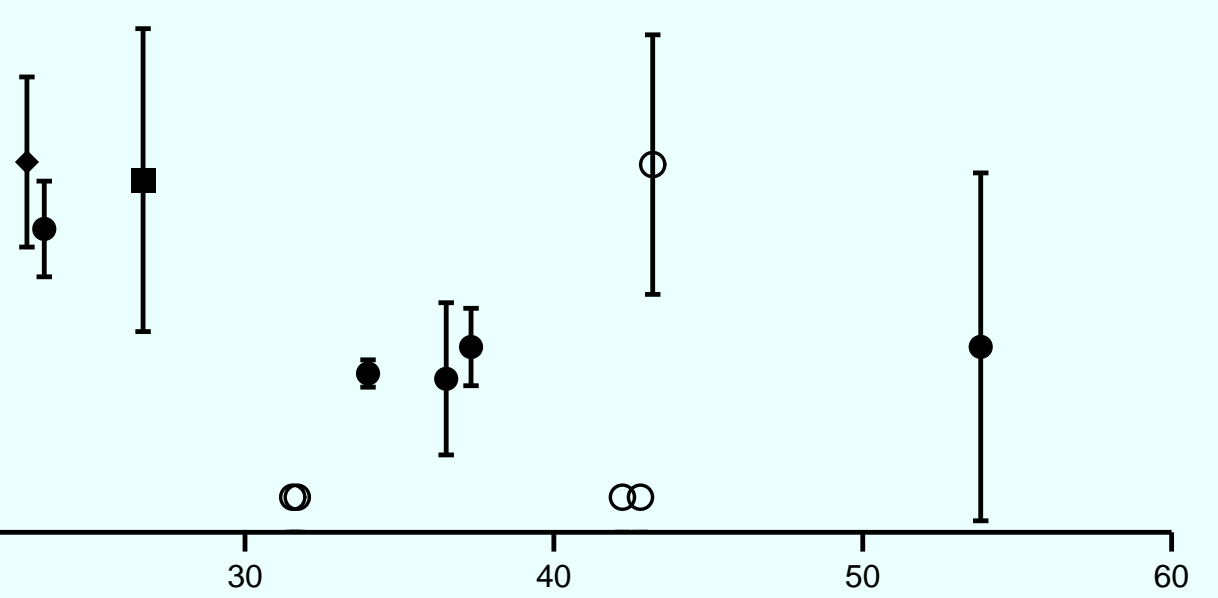

$\infty$ 

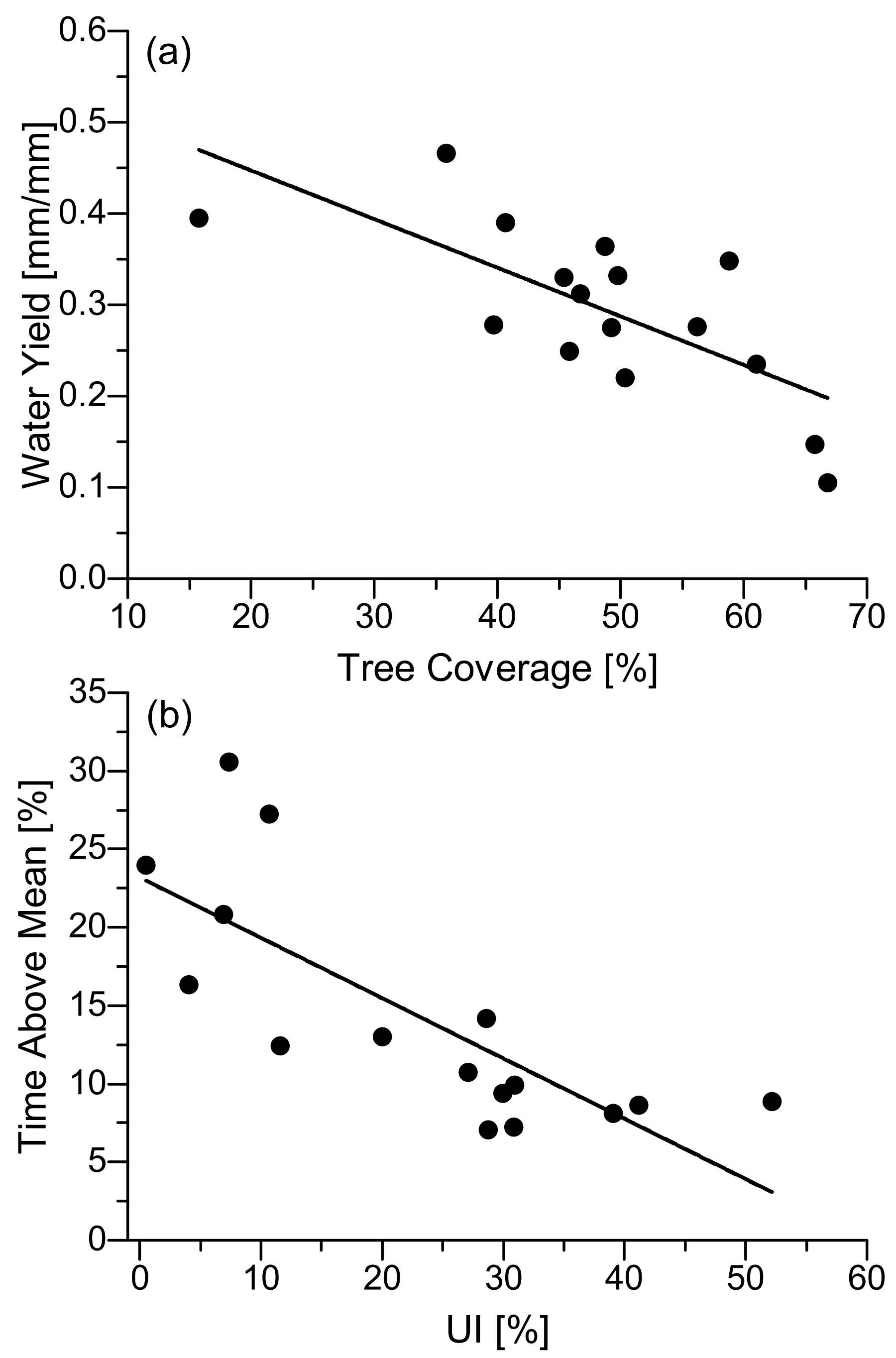